\title{
Metformin prevents nephrolithiasis formation by inhibiting the expression of OPN and MCP-1 in vitro and in vivo
}



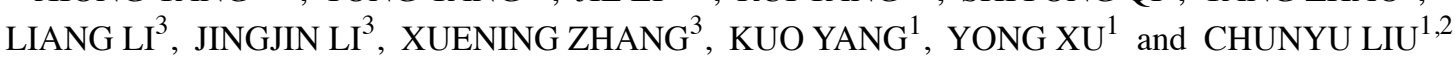 \\ ${ }^{1}$ Department of Urology, Tianjin Institute of Urology, The Second Hospital of Tianjin Medical University; ${ }^{2}$ Urolith Center, \\ ${ }^{3}$ Department of Radiology, The Second Hospital of Tianjin Medical University, Hexi, Tianjin 300211, P.R. China
}

Received August 1, 2018; Accepted January 16, 2019

DOI: $10.3892 / \mathrm{ijmm} .2019 .4084$

\begin{abstract}
Treatment targeting osteopontin (OPN) and monocyte chemoattractant protein 1 (MCP-1) has been recognized as a novel approach in renal crystal formation. The present study was designed to investigate the suppressive effects of metformin on nephrolithiasis formation and its potential mechanism. The cytotoxicity of metformin on MDCK and HK-2 cells was determined using a Cell Counting Kit-8 assay in vitro. Subsequently, the mRNA transcription and protein expression levels of MCP-1 and OPN were detected by reverse transcription-quantitative-polymerase chain reaction analysis, western blot analysis and ELISA. Male Sprague-Dawley rats were divided into a control group, ethylene glycol (EG) group and $\mathrm{EG}+$ metformin group. The expression levels of MCP-1 and OPN and crystal formations were evaluated in renal tissues following an 8-week treatment period. In vitro, metformin significantly inhibited the production of MCP-1 and OPN induced by oxalate at the mRNA and protein expression levels. In vivo, increased expression levels of MCP-1 and OPN were detected in the EG group compared with the controls, and this upregulation was reversed in the EG + metformin group. Renal crystal deposition in the EG + metformin group was markedly decreased compared with that in the EG group. Therefore, the results of the study suggest that metformin suppressed urinary crystal deposit formation, possibly by mediating the expression of inflammatory mediators OPN and MCP-1.
\end{abstract}

\section{Introduction}

The increasing prevalence of nephrolithiasis worldwide is a principal societal issue due to the high financial cost associated

Correspondence to: Dr Chunyu Liu, Department of Urology, Tianjin Institute of Urology, The Second Hospital of Tianjin Medical University, 23 Pingjiang Road, Hexi, Tianjin 300211, P.R. China

E-mail: dr.chunyuliu@hotmail.com

${ }^{*}$ Contributed equally

Key words: nephrolithiasis, osteopontin, monocyte chemoattractant protein 1, rats, Sprague-Dawley, metformin with kidney stone therapy (1-3). Calcium-containing stones comprise $>80 \%$ of kidney stone components, with calcium oxalate $(\mathrm{CaOx})$ stones detected most frequently $(4,5)$. Evidence from previous studies suggested that the induction of hyperoxaluria is the primary risk factor and is an essential requirement for the development of $\mathrm{CaOx}$ nephrolithiasis $(6,7)$. In addition, oxalate is not only a principal constituent of $\mathrm{CaOx}$ stones; however, it additionally influences $\mathrm{CaOx}$ crystal formation, primarily acting on the renal tubular epithelium $(8,9)$. The pathogenesis of $\mathrm{CaOx}$ nephrolithiasis is complex and involves multiple mechanisms that lead towards the formation of kidney stones (10-12). Notably, previous studies have demonstrated that inflammatory mediators osteopontin (OPN) and monocyte chemoattractant protein 1 (MCP-1) are important during the development of $\mathrm{CaOx}$ stones (13-15).

MCP-1, a member of the CC chemokine subfamily, has been demonstrated to serve as a key regulator of the inflammatory response, which is considered to be a potent and specific chemotactic factor for the recruiting and migration of inflammatory cells, particularly monocytes/macrophages, into the inflamed area following tissue injury (13). In addition, evidence suggests that MCP-1 is a key element in various pathological abnormalities associated with renal epithelial cells, including nephrolithiasis (16). OPN, a 44-kDa phosphorylated glycoprotein originally identified in bone, is involved throughout the development of various inflammatory disorders; and the absence or neutralization of OPN results in the amelioration of numerous inflammatory diseases, suggesting that OPN may be a useful target molecule for the treatment of inflammation (17). Perhaps more importantly, OPN may modulate various steps of $\mathrm{CaOx}$ crystallization (15), and contributes importantly to renal $\mathrm{CaOx}$ crystal deposition in experimental animals (15).

Metformin, an antiglycemic biguanide drug used since 1958 and the most commonly prescribed drug for type II diabetes mellitus in the world, has extensive potential benefits, including reduced risk of cancer, increased antioxidant protection and prolonged lifespan (18). In our previous study, it was identified that metformin effectively reduced renal stone formation through renal tubular cell protection and an antioxidant mechanism (19). According to previously published data, metformin may additionally significantly prevent the expression of inflammatory markers in obstructed kidneys (20). 
However, there are no reports, to the best of the authors' knowledge, on the effects of metformin on the expression of inflammatory mediators OPN and MCP-1 in renal tubular cells. Therefore, the purpose of the present study was to test the hypothesis that metformin prevents the development of $\mathrm{CaOx}$ renal stone formation and investigate its potential mechanism regarding OPN and MCP-1.

\section{Materials and methods}

Cell culture. MDCK cells, obtained from the Chinese Academy of Medical Sciences (Shanghai, China), are derived from the canine renal distal tubular epithelium cell line. HK-2 cells, additionally obtained from the Chinese Academy of Medical Sciences, are derived from the human renal proximal tubular epithelium cell line. Routinely, the cells were maintained in Dulbecco's modified Eagle's medium (DMEM; Gibco; Thermo Fisher Scientific, Inc., Waltham, MA, USA), supplemented with $10 \%$ fetal bovine serum (Gibco; Thermo Fisher Scientific, Inc.), $4.5 \mathrm{mM}$ glucose, $100 \mathrm{IU} / \mathrm{ml}$ penicillin and $100 \mu \mathrm{g} / \mathrm{ml}$ streptomycin in a humidified incubator with $5 \% \mathrm{CO}_{2}$ at $37^{\circ} \mathrm{C}$.

Cytotoxicity assay. The cytotoxicity towards MDCK and HK-2 cells was investigated using a Cell Counting Kit-8 (CCK-8; Dojindo Molecular Technologies, Inc., Kumamoto, Japan) assay following various treatments, according to the manufacturer's protocol. The cells were seeded in 96-well plates at a density of $5 \times 10^{3}$ cells per well and cultured overnight. Subsequently, fresh medium containing metformin (Sigma-Aldrich; Merck KGaA, Darmstadt, Germany) at different concentrations $(0,0.3125,0.625,1.25,2.5,5,10,20$ and $40 \mathrm{mM}$ ) was added to replace the culture medium for $48 \mathrm{~h}$ at $37^{\circ} \mathrm{C}$. Following incubation, the culture medium containing the metformin was removed, and $100 \mu \mathrm{l}$ fresh medium and $10 \mu \mathrm{l}$ CCK-8 solution were added to each well. Following incubation for an additional $4 \mathrm{~h}$ at $37^{\circ} \mathrm{C}$, the absorbance was measured spectrophotometrically at a wavelength of $450 \mathrm{~nm}$ using a microplate reader (SpectraMax Plus384; Molecular Devices, LLC, Sunnyvale, CA, USA). Cell viability was measured as a percentage of that of the control (untreated) cells. For each concentration of metformin, the mean values of the absorbance rates from eight wells were calculated. The maximum safe concentration determined by the CCK- 8 assay was used in the following experiments.

$H K-2$ cell and MDCK cell in vitro administration. The HK-2 cells and MDCK cells were routinely subcultured until $70-80 \%$ confluence, and were subsequently washed with serum-free DMEM and incubated for $24 \mathrm{~h}$. Thereafter, the cells from the two cell lines were simultaneously exposed to sodium oxalate $(1 \mathrm{mM})$ in the presence or absence of metformin (HK-2, 1. $25 \mathrm{mM}$; MDCK, $5 \mathrm{mM}$ ). Subsequently, the cells were harvested for mRNA isolation following 6-h incubation and for protein isolation following 24-h incubation. The control cultures underwent the same procedures as the treated cells but without exposure to sodium oxalate or metformin. The durations of cell exposure and concentration of sodium oxalate were based on the findings reported previously (21-23). The metformin concentrations used were selected according to the results of the cytotoxicity assay. All experiments were repeated at least three times with three replications in each.

Experimental animals and protocol. All animal procedures were conducted in strict compliance with the Guide for the Care and Use of Laboratory Animals published by the US National Institutes of Health (publication no. 85-23; revised 1996; Bethesda, MD, USA). Ethical protocols were approved by the Animal Care and Use Committee of Tianjin Medical University (Tianjin, China) and the Ethics Committees of Tianjin Medical University. Healthy male Sprague-Dawley rats $(\mathrm{n}=18$; age, 8 weeks-old; body weight, 180-220 g) were provided by the Experimental Animal Center of Tianjin Medical University (Tianjin, China) and housed under specific pathogen-free conditions of constant temperature $\left(24 \pm 2^{\circ} \mathrm{C}\right)$ and humidity $(55 \pm 5 \%)$, in a 12 -h alternating light-dark cycle and with free access to standard rat chow. The animals were randomly divided into three groups, with six animals per treatment group: Group 1 (control group) was treated with free access to standard rat chow and distilled water for the entire 8-week study period; group 2 [ethylene glycol (EG) group] was fed standard rat chow and administered with free access to $0.75 \%$ (vol/vol) EG in distilled water for 8 weeks to induce $\mathrm{CaOx}$ deposition in the kidneys (24-26); group 3 (EG + metformin group) followed the same protocol as group 2 but also received metformin dissolved in distilled water by oral gavage at $200 \mathrm{mg} / \mathrm{kg} /$ day throughout the 8 -week experimental period $(27,28)$. Animals in groups 1 and 2 received oral gavage of distilled water (control) at an equal volume as in group 3 during the treatment. Water and fluid consumption were recorded daily. The rats were weighed prior to and during treatment to assess growth. At $24 \mathrm{~h}$ prior to sacrifice, the 8-week-old rats were transferred to metabolic cages, and 24-h urine was collected. At the end of the 8-week administration period, non-enhanced CT was performed on all the rats using a 64-slice GE Lightspeed CT scanner with $0.625-\mathrm{mm}$ sections (GE Healthcare, Chicago, IL, USA). Under anesthesia with an intraperitoneal injection of pentobarbital sodium (40 mg/ $\mathrm{kg}$ body weight; Sigma-Aldrich; Merck KGaA), the animals were sacrificed by rapid cervical dislocation, which is a widely accepted humane sacrifice method for experimental animals. Blood samples and kidney tissues were collected from six rats per group following sacrifice. All efforts were made to minimize animal suffering. The blood samples were maintained on wet ice until centrifugation at $112 \mathrm{x} \mathrm{g}$ at $4^{\circ} \mathrm{C}$ for $10 \mathrm{~min}$, following which serum was collected and stored at $-20^{\circ} \mathrm{C}$. For kidney extraction, the right unilateral kidney specimens were frozen in liquid nitrogen, and stored at $-80^{\circ} \mathrm{C}$ for the western blot and reverse transcription-quantitative polymerase chain reaction (RT-qPCR) analyses, and the contralateral specimens were fixed with $10 \%$ formaldehyde for $24 \mathrm{~h}$ at room temperature and embedded in paraffin for immunohistochemical analysis and the detection of kidney crystal formation.

$R T-q P C R$ analysis. Cells from the two cell lines were cultured and treated as indicated. Total RNA was isolated from the cultured cells and rat kidney tissues with TRIzol ${ }^{\circledR}$ reagent (Takara Biotechnology Co., Ltd., Dalian, China) according to the manufacturer's protocol. The RNA samples typically 
Table I. Primers used for reverse transcription-quantitative polymerase chain reaction assays.

\begin{tabular}{llll}
\hline Species & \multicolumn{1}{c}{ Gene (Protein) } & Forward primer sequence, 5'-3' & \multicolumn{1}{c}{ Reverse primer sequence, 5'-3' } \\
\hline Homo sapiens & SPP1 (OPN) & GAAGTTTCGCAGACCTGACAT & GTATGCACCATTCAACTCCTCG \\
& CCL2 (MCP-1) & CTCAGCCAGATGCAATCAAT & GCTTCTTTGGGACACTTGCT \\
& GAPDH (GAPDH) & ACCCAGAAGACTGTGGATGG & TCTAGACGGCAGGTCAGGTC \\
Canis lupus familiaris & SPP1 (OPN) & CCGAGGTGATAGTGTGGCTTA & GGAAAGTAGGACGGCATTGA \\
& CCL2 (MCP-1) & CCTCTGCCTGCTGCTCATA & GCTTCTTTGGGACACTTGCT \\
& GAPDH (GAPDH) & GACGACATCAAGAAGGTAGTG & AGGTGGAAGAGTGGGTGT \\
Rattus norvegicus & SPP1 (OPN) & AAGCGTGGAAACACACAGC & TTTGGAACTCGCCTGACTG \\
& CCL2 (MCP-1) & GATCTCAGTGCAGAGGCTCG & TGCTTGTCCAGGTGGTCCAT \\
& GAPDH (GAPDH) & GGCATTGCTCTCAATGACAA & ATGTAGGCCATGAGGTCCAC \\
\hline
\end{tabular}

had an A260/280 ratio between 1.9 and 2.1. The quantity and purity of the obtained total RNA samples were determined by NanoDrop (NanoDrop Technologies; Thermo Fisher Scientific, Inc., Wilmington, DE, USA). Total RNA (3 $\mu \mathrm{g})$ was reverse transcribed into cDNA using the High-Capacity cDNA RT kit (Invitrogen; Thermo Fisher Scientific, Inc.) according to the manufacturer's protocol. The RT-qPCR analysis was performed with an Illumina ${ }^{\circledR}$ Eco Real Time PCR system (Model EC-100-1001; Illumina, Inc., San Diego, CA, USA). The primer sequences are listed in Table 1. Each 10- $\mu 1$ reaction contained the following: $5 \mu$ l Maxima SYBR Green/Fluorescein qPCR Master mix (2X; Thermo Fisher Scientific, Inc.), a necessary volume to $0.2-0.6 \mu \mathrm{M}$ each primer, a volume with $10 \mathrm{ng}$ cDNA and the volume difference was made up with diethylpyrocarbonate-treated water. The thermocycling conditions consisted of incubation at $94^{\circ} \mathrm{C}$ for $3 \mathrm{~min}$, followed by $38-45$ cycles at $94^{\circ} \mathrm{C}$ for $30 \mathrm{sec}$, at $58^{\circ} \mathrm{C}$ for $30 \mathrm{sec}$ and at $72^{\circ} \mathrm{C}$ for $1 \mathrm{~min}$. The relative quantification of mRNA expression levels was determined using the comparative quantification cycle $(\mathrm{Cq})$ method $\left(2^{-\Delta \Delta \mathrm{Cq}}\right.$ method) (29). Negative controls (samples without cDNA) were included in all experiments. The specificity of each PCR reaction was verified by melt-curve analysis and by checking the PCR products on a $1.5 \%$ agarose gel.

Western blot analysis. Cells from the two cell lines were cultured and treated as indicated. Proteins were extracted from the cultured cells and rat kidney tissues with a protein extraction kit (Nanjing KeyGen Biotech Co., Ltd., Nanjing, China), and the cells were lysed with radioimmunoprecipitation assay buffer (Beijing Solarbio Science \& Technology Co., Ltd., Beijing, China). The protein concentrations of samples were determined using the bicinchoninic acid method (Pierce; Thermo Fisher Scientific, Inc.). The proteins (25 $\mu \mathrm{g})$ were separated by $10 \%$ SDS-PAGE and transferred onto a nitrocellulose membrane (EMD Millipore, Billerica, MA, USA). The membranes were blocked with $5 \%$ non-fat milk in TBS with Tween-20 for $30 \mathrm{~min}$ at room temperature. Subsequently, the membranes were incubated with primary antibodies against OPN (cat. no. ab95090; 1:1,000; Abcam, Cambridge, MA, USA), MCP-1 (cat. no. ab21396; 1:1,000; Abcam) and $\beta$-actin (cat. no. 3700; 1:1,000; Cell Signaling Technology, Inc., Danvers, MA, USA) overnight at $4^{\circ} \mathrm{C}$. Antibody binding was detected following incubation with appropriate secondary antibodies conjugated to horseradish peroxidase (cat. no. 12262; 1:1,000; Cell Signaling Technology, Inc.) for $1 \mathrm{~h}$ at room temperature. The detection of specific bands was achieved using enhanced chemiluminescence reagent (Pierce; Thermo Fisher Scientific, Inc.). Images were captured using a the Syngene G: Box Chemi XR5 bioimaging system (Syngene, Frederick, MD, USA) and analyzed with Image Pro Plus 6.0 software (Media Cybernetics, Inc., Rockville, MD, USA).

ELISA. Cells from the two cell lines were cultured and treated as indicated. The cell culture supernatants were collected following incubation for $24 \mathrm{~h}$, and the production of OPN (cat. nos. CSB-E08392h and CSB-E07013c; Cusabio, Wuhan, China) and MCP-1 (cat. nos. CSB-E04655h and CSB-E15747c; Cusabio) were measured using commercially available ELISA kits, according to the manufacturer's protocol.

Immunohistochemical staining. The kidneys were fixed with formaldehyde $(10 \%)$ at room temperature for $24 \mathrm{~h}$, and subsequently embedded in paraffin and cut into $4-\mu \mathrm{m}$ sections. For immunohistochemical staining, following heating at $65^{\circ} \mathrm{C}$ for $2 \mathrm{~h}$, the sections were de-waxed twice for $10 \mathrm{~min}$ with dimethylbenzene. Subsequent to de-waxing, the sections were dehydrated with successive concentrations of ethanol $(100,95$, 90 and $80 \%$ ) for $5 \mathrm{~min}$ at each concentration. The sections were later incubated in citrate buffer in a box and heated to $90-98^{\circ} \mathrm{C}$ in a pressure cooker. After $2 \mathrm{~min}$, the sections were removed and naturally cooled. Subsequent to the removal of the citrate buffer and washing with PBS, the sections were incubated with $3 \% \mathrm{H}_{2} \mathrm{O}_{2}$ for 15 min to block endogenous peroxidase activity and washed with PBS ( $\mathrm{pH} 7.4)$ for 5 min each at room temperature. Non-specific protein binding was blocked with $5 \%$ bovine serum albumin (Dako; Agilent Technologies, Inc., Santa Clara, CA, USA) for $30 \mathrm{~min}$ at $37^{\circ} \mathrm{C}$. The sections were subsequently incubated with primary antibody overnight at $4^{\circ} \mathrm{C}$ (OPN; 1:200; cat. no. ab8448; MCP-1; 1:150; cat. no. ab25124; Abcam). Following this, the sections were incubated with biotinylated secondary antibody (cat. no. ab6721; 1:1,000; Abcam) at $37^{\circ} \mathrm{C}$ for $30 \mathrm{~min}$ and subsequently developed using diaminobenzidine. Finally, the tissue sections were counterstained with hematoxylin at room temperature for $3 \mathrm{~min}$, washed for 10 min and dehydrated with ethanol, and subsequently treated 
with dimethylbenzene and sealed for microscopic analysis. The slides were examined using a light microscope (Nikon ECLIPSE 90i microscope; Nikon Corporation, Tokyo, Japan; magnification, $\mathrm{x} 100$ and $\mathrm{x} 400$ ).

Serum and urinary biochemistry. The concentrations of urinary oxalate $\left(\mathrm{O}_{\mathrm{X}}\right)$ were determined with commercially available kits (Trinity Biotech USA, Inc., Jamestown, NY, USA). Calcium in urine and serum levels of phosphate $(\mathrm{P})$, calcium $(\mathrm{Ca})$, magnesium $(\mathrm{Mg})$ and creatinine were measured on a routine autoanalyzer system (Mindray BS-2000M; Mindray Medical International Ltd., Shenzhen, China). Urinary $\mathrm{pH}$ and volume were detected manually.

Detection of kidney crystal formation. Kidney tissue samples were collected from either the control or treated rats, embedded in paraffin and sectioned at $4.0-\mu \mathrm{m}$. The tissue slices were subsequently stained with hematoxylin for $8 \mathrm{~min}$ and eosin for 3 min (H\&E; Beijing Solarbio Science \& Technology Co., Ltd.) at room temperature, and sealed rapidly for polarized light optical microscopic analysis. In addition, cross sections were stained using a previously described Pizzolato staining method to detect crystals that contain $\mathrm{CaOx}(30,31)$. The renal crystal number per high-powered field was counted in 10 randomly selected fields (magnification, x400) and quantified by standard validation as described in detail previously $(8,21)$. The distribution of renal crystallization in each section was quantified by calculating the percentage (ratio) of the area containing crystals to low-powered field in 10 randomly selected fields (magnification, x100) using Image Pro Plus 6.0 software (Media Cybernetics, Inc.), as described previously $(30,32)$. In total, two independent examiners assessed the representative H\&E-stained paraffin sections for each kidney and calculated the average number of crystals deposited, respectively.

Statistical analysis. All data are expressed as the mean \pm standard deviation of a minimum of three replicates in independent experiments. Statistical analyses were performed using the Wilcoxon rank-sum test, two-tailed unpaired t-test and one-way analysis of variance with Bonferroni's post hoc test where appropriate using SPSS software, version 20 (IBM Corp., Armonk, NY, USA). P $<0.05$ was considered to indicate a statistically significant difference.

\section{Results}

Cytotoxicity. As presented in Fig. 1, the CCK-8 assay results demonstrated a dose-dependent toxic effect with increasing concentrations of metformin on HK-2 cells and MDCK cells under starved conditions. No significant cytotoxicity was observed at concentrations $\leq 2.5 \mathrm{mM}$ in HK-2 cells or $5 \mathrm{mM}$ in MDCK cells. These results suggest that low doses of metformin did not decrease cell viability in either cell line, but that exposure to metformin caused significant cytotoxicity at relatively higher doses (metformin $>2.5 \mathrm{mM}$ in HK-2 cells, metformin $>5 \mathrm{mM}$ in MDCK cells). The concentration gradient was improved based on our previous experiments using MMT (19). In the present study, $1.25 \mathrm{mM}$ for HK-2 cells and $5 \mathrm{mM}$ for MDCK cells were selected as
Table II. Body weight and water intake prior to and following treatment.

\begin{tabular}{llcc}
\hline Measurement & Control & EG & EG + metformin \\
\hline $\begin{array}{l}\text { Body weight, g } \\
\text { 0 week }\end{array}$ & & & \\
2 weeks & $253 \pm 18$ & $249 \pm 17$ & $241 \pm 19$ \\
4 weeks & $324 \pm 19$ & $335 \pm 18$ & $313 \pm 17$ \\
6 weeks & $392 \pm 20$ & $388 \pm 22$ & $363 \pm 21$ \\
8 weeks & $461 \pm 25$ & $457 \pm 27$ & $405 \pm 24^{\mathrm{a}, \mathrm{b}}$ \\
Fluid consumption, ml x & & & \\
day $^{-1}$ x kg body weight & & \\
2 weeks & & & \\
4 weeks & $105 \pm 11$ & $110 \pm 12$ & $108 \pm 11$ \\
6 weeks & $112 \pm 9$ & $108 \pm 11$ & $113 \pm 12$ \\
8 weeks & $115 \pm 12$ & $112 \pm 10$ & $109 \pm 12$ \\
\hline
\end{tabular}

Data are presented as the mean \pm standard deviation. ${ }^{\mathrm{a}} \mathrm{P}<0.05$, control, vs. $\mathrm{EG}+$ metformin; ${ }^{\mathrm{b}} \mathrm{P}<0.05$, $\mathrm{EG}$, vs. $\mathrm{EG}+$ metformin. Statistical analyses were performed by one-way analysis of variance. EG, ethylene glycol.

the respective exposure doses for metformin in the subsequent experiments, at which no significant cytotoxicity was observed.

Metformin attenuates the upregulation of OPN and MCP-1 induced by oxalate in vitro. In order to evaluate whether metformin attenuates the upregulation of OPN and MCP-1 induced by $\mathrm{Ox}$, changes in the expression of OPN and MCP-1 in response to metformin in vitro were measured. As presented in Fig. 2A, the mRNA expression levels of OPN and MCP-1 were significantly increased in HK-2 cells following sodium oxalate exposure compared with the untreated controls $(\mathrm{P}<0.05)$. In addition, metformin treatment attenuated the Ox-induced increase of OPN and MCP-1 $(\mathrm{P}<0.05)$. As expected, exposure of the HK-2 cells to Ox elicited increases in the protein expression of OPN and MCP-1 compared with that in the untreated controls, although the upregulation of MCP-1 was not statistically significant $(\mathrm{P}>0.05$; Fig. $2 \mathrm{~B})$. Consistent with the mRNA levels, metformin co-treatment reduced the increased protein expression of OPN and MCP-1, although the attenuation in the protein expression of MCP-1 was not statistically significant ( $P>0.05$; Fig. 2B). The same results were obtained in MDCK cells (Fig. 3).

In addition, the concentrations of MCP-1 and OPN in the cell culture supernatants were determined in HK-2 cells and MDCK cells by ELISA, as presented in Fig. 4. Sodium oxalate exposure markedly increased the production of OPN and MCP-1 compared with that in the untreated controls in the two cell lines $(\mathrm{P}<0.05)$; however, metformin treatment abrogated the Ox-induced increases in the expression of OPN and MCP-1 in the cell culture supernatants.

Body weight and fluid consumption results. The body weights increased gradually in all the three groups throughout the time period. However, the body weights in the EG + metformin 
A

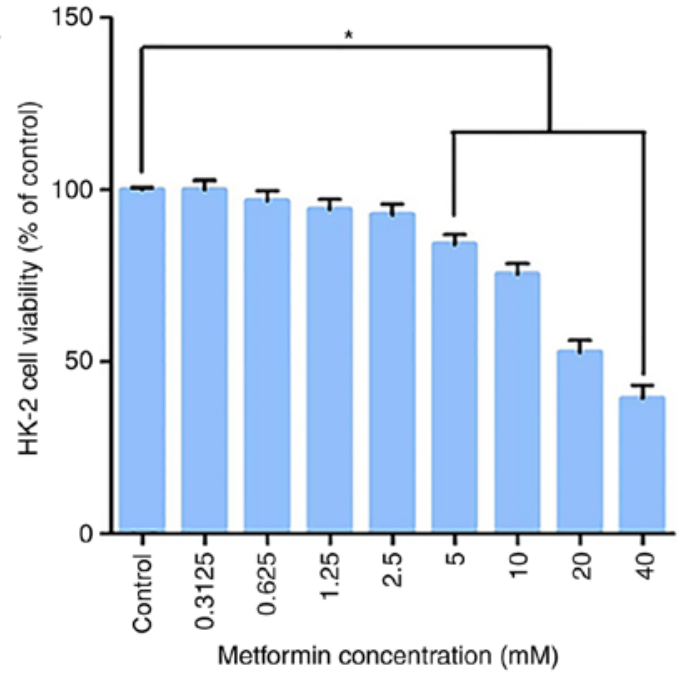

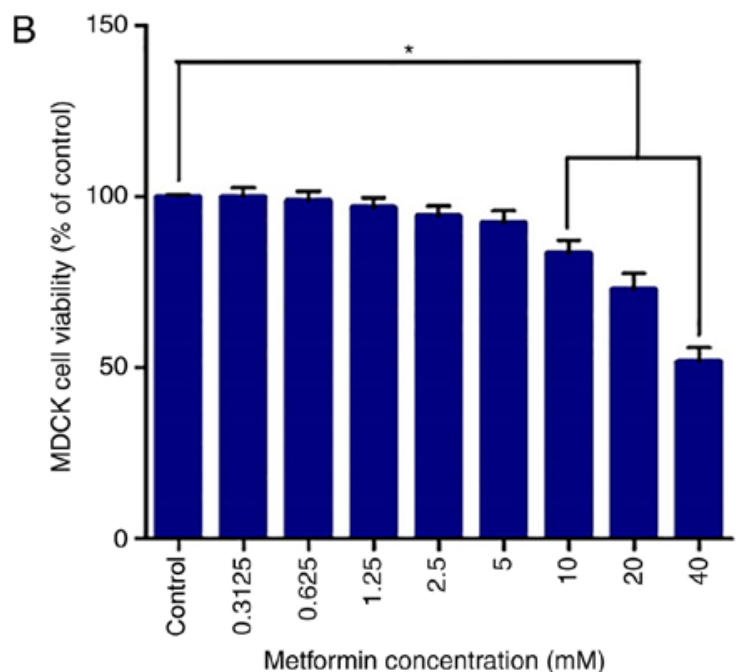

Figure 1. Effect of various concentrations of metformin on cytotoxicity in cultured HK-2 cells and MDCK cells. (A) HK-2 cells were treated with the indicated concentrations $(0.3125-40 \mathrm{mM})$ of metformin for $48 \mathrm{~h}$. (B) MDCK cells were treated with the indicated concentrations $(0.3125-40 \mathrm{mM})$ of metformin for $48 \mathrm{~h}$. Viability of the cells was assessed using a Cell-Counting-Kit-8 assay. The percentage of cell viability was relative to the untreated control cells. Values are presented as the mean \pm standard deviation of three independent experiments. " $\mathrm{P}<0.05$ vs. control. Statistical analyses were performed by one-way analysis of variance.
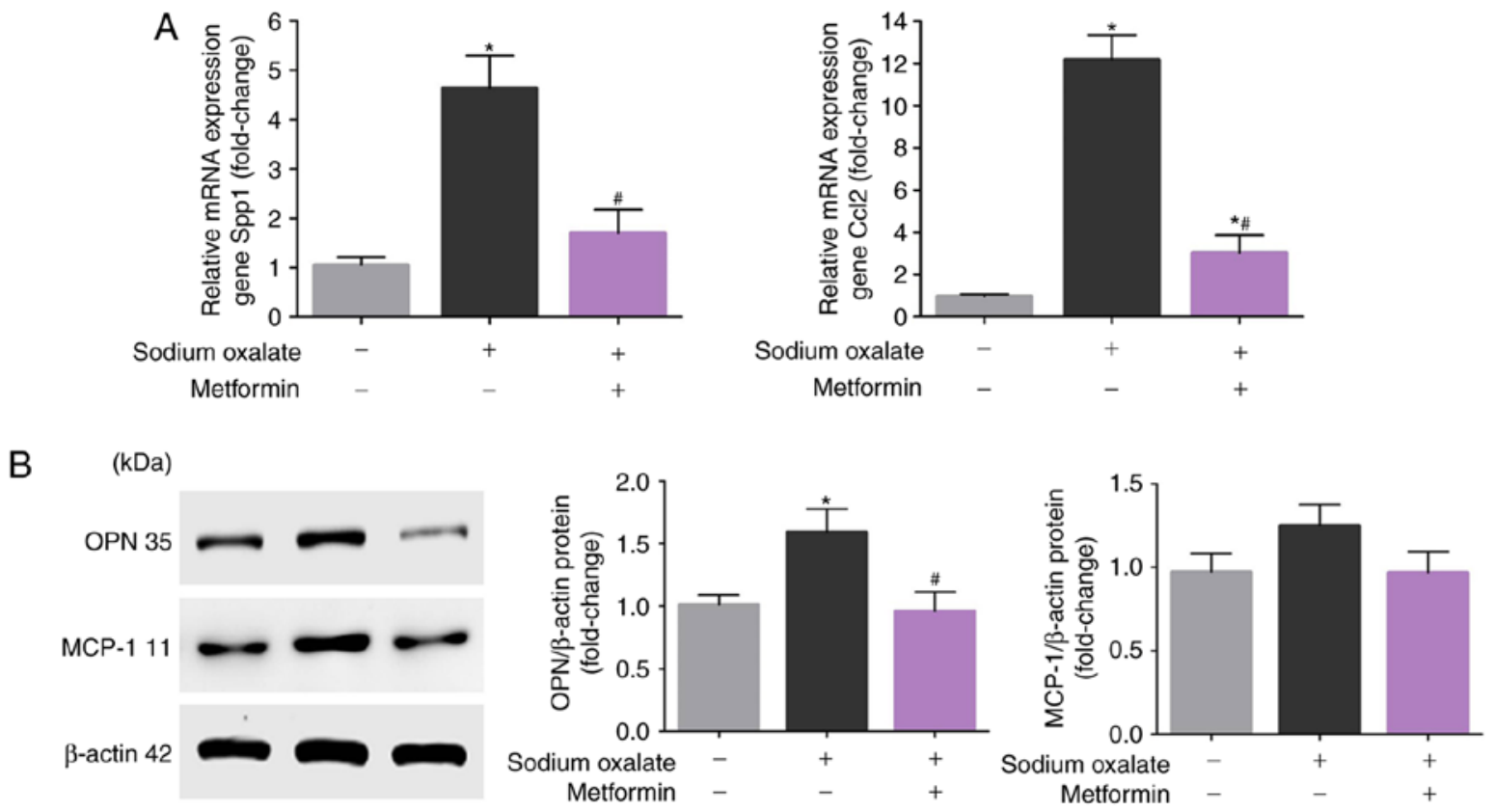

Figure 2. Evaluation of the mRNA transcription and protein expression of OPN and MCP-1 in HK-2 cells. (A) Reverse transcription-quantitative polymerase chain reaction analysis of expression levels of OPN (left panel) and MCP-1 (right panel) in HK-2 cells; values are corrected for GAPDH. Protein expression of (B) OPN (left panel) and MCP-1 (right panel) in HK-2 cells. The data are presented as the mean \pm standard deviation of three independent experiments. ${ }^{\text {"P }}<0.05$ vs. control group; ${ }^{*} \mathrm{P}<0.05$ vs. sodium oxalate group. Statistical analyses were performed by one-way analysis of variance. OPN, osteopontin; MCP-1, monocyte chemoattractant protein 1 .

group increased at a slower rate than in the control group and EG group; at the end of the 8-week treatment period, the differences were statistically significant. The fluid consumption adjusted by the body weight was not the different at any time point in the three groups. The animals in the EG group and $\mathrm{EG}+$ metformin group consumed similar quantities of EG, and no significant difference in fluid consumption was observed between either of these groups and the control (Table II).
Serum and urinary biochemistry results. The serum biochemical analysis showed that $\mathrm{Ca}, \mathrm{Mg}$ and creatinine remained essentially stable with no significant differences in any of the groups. Compared with the controls, serum $\mathrm{P}$ in the EG group was significantly higher $(\mathrm{P}<0.05)$, whereas this effect was ameliorated, to a certain extent, in the EG + metformin group. There was no significant alteration in urinary volume or $\mathrm{pH}$ in any of the groups following 8 weeks of administration. As expected, urinary Ox excretion was significantly increased 

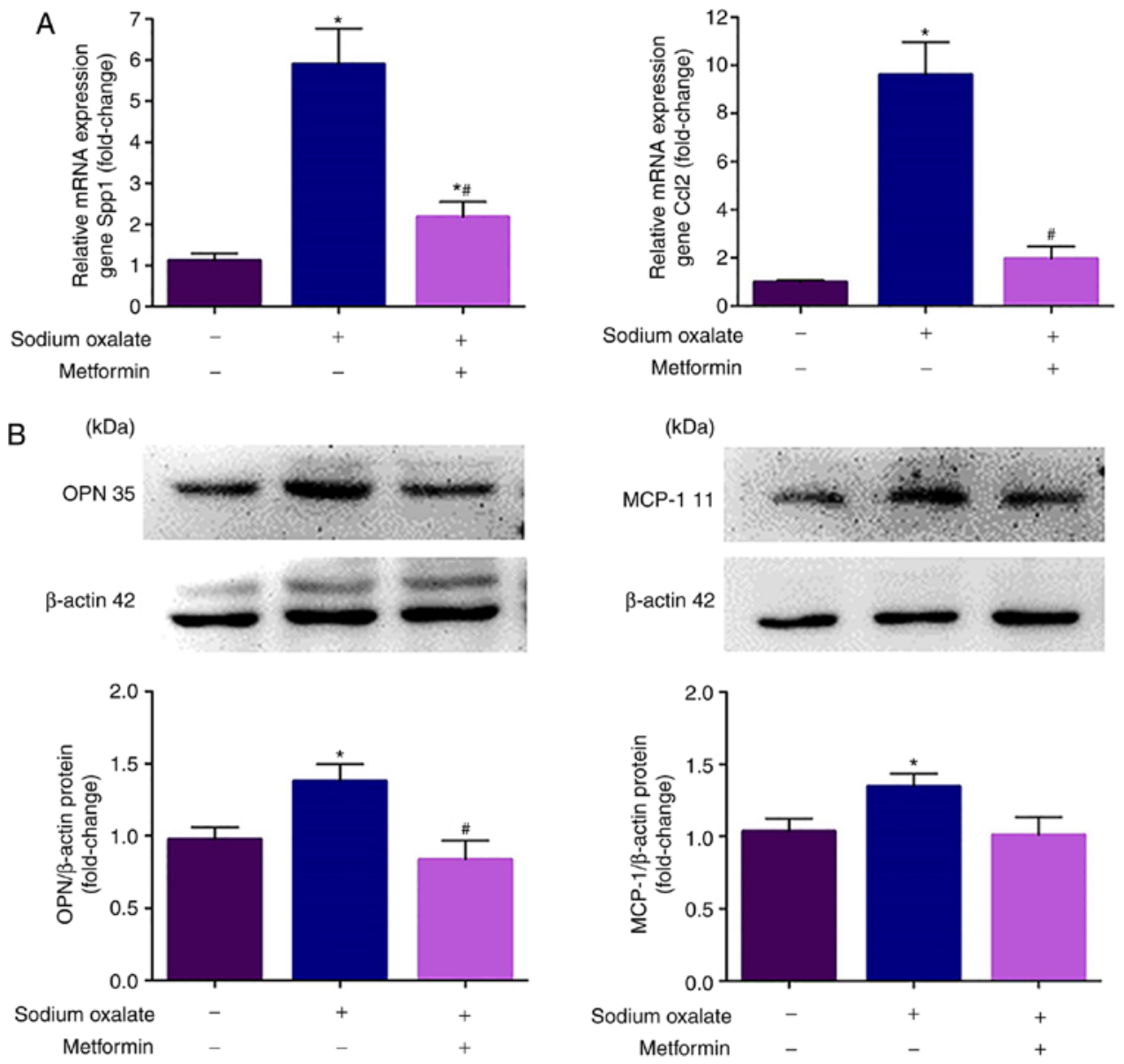

Figure 3. Evaluation of the mRNA transcription and protein expression of OPN and MCP-1 in MDCK cells. (A) Reverse transcription-quantitative polymerase chain reaction analysis of expression levels of OPN (left panel) and MCP-1 (right panel) in MDCK cells; values were corrected for GAPDH. Protein expression of (B) OPN (left panel) and MCP-1 (right panel) in MDCK cells. The data are presented as the mean \pm standard deviation of three independent experiments ${ }^{*} \mathrm{P}<0.05$ vs. control group; ${ }^{~} \mathrm{P}<0.05$ vs. sodium oxalate group. Statistical analyses were performed by one-way analysis of variance. OPN, osteopontin; MCP-1, monocyte chemoattractant protein 1 .

A

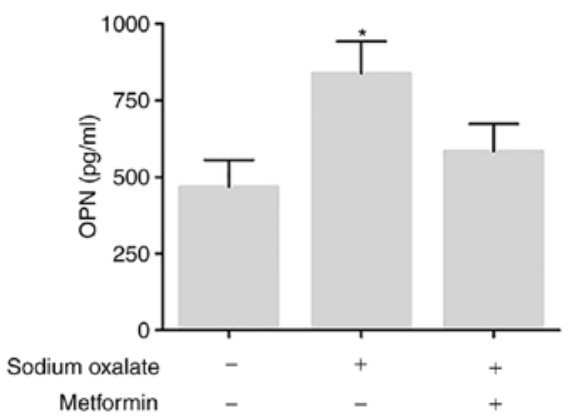

C

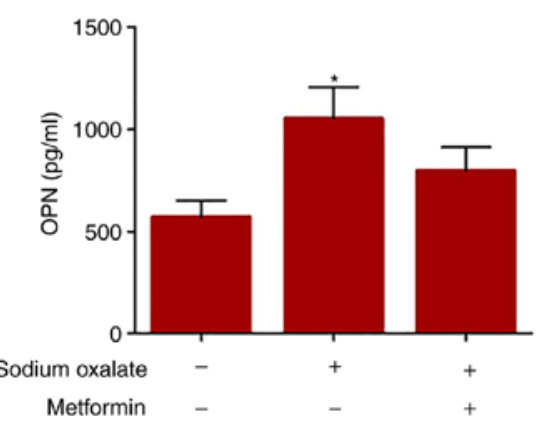

B

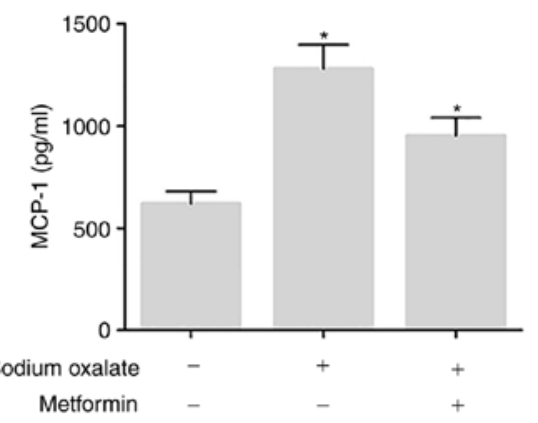

D

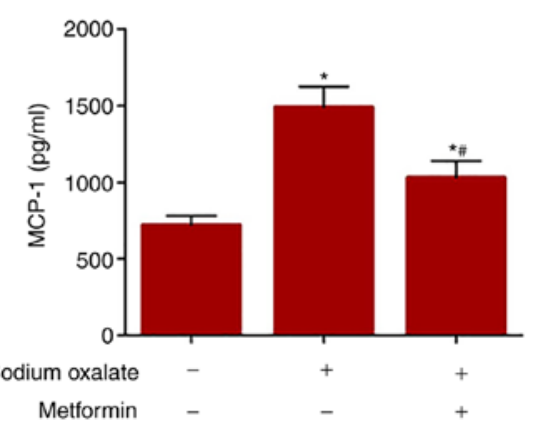

Figure 4. Production of OPN and MCP-1 in the cell culture supernatants of HK-2 cells and MDCK cells. Expression of (A) OPN (upper-left panel) and (B) MCP-1 (upper-right panel) in HK-2 cell culture supernatants. Expression of (C) OPN (lower-left panel) and (D) MCP-1 (lower-right panel) in MDCK cell culture supernatants. The data are presented as the mean \pm standard deviation of three independent experiments. $\mathrm{P}<0.05$ vs. control group; ${ }^{*} \mathrm{P}<0.05$ vs. sodium oxalate group. Statistical analyses were performed by one-way analysis of variance. OPN, osteopontin; MCP-1, monocyte chemoattractant protein 1. 
Table III. Serum and urinary biochemistry.

\begin{tabular}{lrrr}
\hline Factor & Control & EG & EG + metformin \\
\hline Serum & & & \\
Creatinine, mg/dl & $0.34 \pm 0.02$ & $0.36 \pm 0.03$ & $0.35 \pm 0.04$ \\
Calcium, mg/dl & $10.12 \pm 0.35$ & $10.21 \pm 0.36$ & $10.06 \pm 0.40$ \\
Phosphate, mg/dl & $6.14 \pm 0.36$ & $7.88 \pm 0.56^{\mathrm{a}}$ & $7.11 \pm 0.44$ \\
Magnesium, mg/dl & $2.52 \pm 0.32$ & $2.65 \pm 0.45$ & $2.33 \pm 0.37$ \\
Urine & & & $23.67 \pm 5.11$ \\
Volume, ml & $21.98 \pm 3.11$ & $24.62 \pm 4.78$ & $7.46 \pm 0.37$ \\
pH & $7.68 \pm 0.36$ & $7.55 \pm 0.46$ & $2.98 \pm 0.43$ \\
Calcium, mg/day & $3.16 \pm 0.28$ & $3.22 \pm 0.37$ & $13.16 \pm 2.53^{\mathrm{a}, \mathrm{b}}$ \\
Oxalate, mg/day & $1.56 \pm 0.47$ & $19.42 \pm 3.12^{\mathrm{a}}$ & \\
\hline
\end{tabular}

Data are presented as the mean \pm standard deviation. ${ }^{\mathrm{a}} \mathrm{P}<0.05$, control, vs. $\mathrm{EG}$ or $\mathrm{EG}+$ metformin; ${ }^{\mathrm{b}} \mathrm{P}<0.05, \mathrm{EG}$, vs. EG + metformin. Statistical analyses were performed by one-way analysis of variance. EG, ethylene glycol.

Table IV. Statistical analysis of functional expression of OPN and MCP-1 in rat kidneys following 8 weeks of treatment.

\begin{tabular}{|c|c|c|c|c|c|c|c|c|c|c|}
\hline \multirow[b]{2}{*}{ Group } & \multicolumn{5}{|c|}{ OPN } & \multicolumn{5}{|c|}{ MCP-1 } \\
\hline & - & \pm & + & ++ & +++ & - & \pm & + & ++ & +++ \\
\hline Control & 0 & 4 & 2 & 0 & 0 & 0 & 5 & 1 & 0 & 0 \\
\hline EG & 0 & 0 & 1 & $5^{\mathrm{a}, \mathrm{b}}$ & 0 & 0 & 0 & 2 & $4^{\mathrm{a}, \mathrm{b}}$ & 0 \\
\hline $\mathrm{EG}+$ metformin & 0 & 4 & 1 & 1 & 0 & 0 & 2 & 3 & 1 & 0 \\
\hline
\end{tabular}

Summary data from quantitative analysis of the immunohistochemical distribution of OPN and MCP-1 in rat kidneys following 8 weeks of treatment via the Wilcoxon rank-sum test $(n=6)$. ${ }^{a} \mathrm{P}<0.05$, EG, vs. control; ${ }^{\mathrm{b}} \mathrm{P}<0.05$, EG, vs. EG + metformin. Expression levels of OPN and MCP-1 were carefully evaluated. -, negative expression; +/-, positive rate of expression $<25 \%$; + , positive rate of expression $<50 \%$; ++ , positive rate of expression $<75 \%$; and +++ , positive rate of expression $>75 \%$. The numbers listed in this table represent the total number of animals with a negative or positive result in each group following 8 weeks of treatment. OPN, osteopontin; MCP-1, monocyte chemoattractant protein 1; EG, ethylene glycol.

with EG treatment compared with the control group $(\mathrm{P}<0.05)$. Of note, metformin, when administered together with EG, not only significantly ameliorated urinary Ox excretion $(\mathrm{P}<0.05)$; however, additionally led to a non-significant fall in urinary Ca excretion compared with the control group and EG group (Table III).

Metformin restricts EG-induced renal $O P N$ and $M C P-1$ activation in vivo. The present study then determined whether the in vivo results were recapitulated in the HK-2 cells and MDCK cells. Consistent with the in vitro data, the mRNA transcription and protein expression levels of OPN and MCP-1 were markedly increased following treatment with EG for 8 weeks compared with those in the model control rats $(\mathrm{P}<0.05)$, and the upregulation of OPN and MCP-1 was significantly decreased in the $\mathrm{EG}+$ metformin group, compared with that in the EG group $(\mathrm{P}<0.05$; Fig. 5).

To further elucidate the differences in the expression of OPN and MCP-1, immunohistochemistry was performed on the kidneys of the rat models following the 8-week treatment period. As presented in Fig. 6, strong immunohistochemical staining for OPN and MCP-1 was observed in the luminal side of renal tubular epithelial cells in the EG-treated group, particularly in the pericrystal region; OPN and MCP-1 are presented as light brown in the control group and EG + metformin group. This observation is consistent with the above finding that the expression levels of OPN and MCP-1 were markedly increased $(\mathrm{P}<0.05$; Table IV) following treatment in the EG group compared with those in the control group and EG + metformin group.

Metformin ameliorates EG-induced renal crystal formation in the rat model. Crystallization was observed as white dots in the kidney tissues in the thin-slice reconstructions of non-enhanced CT images (Fig. 7). The results demonstrated no significant kidney crystals in any field of the renal parenchyma in the control group $(0 / 6)$ nor in the $\mathrm{EG}+$ metformin group $(0 / 6)$. By contrast, in the rats treated with $\mathrm{EG}$, the majority of the rat kidneys (5/6) were shown to manifest renal crystal depositions. Polarized light optical microscopic examination of the kidneys from the control group showed no kidney crystals in any field (data not shown). As presented in Fig. 8A and B, renal crystal deposits were present predominantly in the renal tubular lumen at the papilla and in the border between the renal cortex 
A

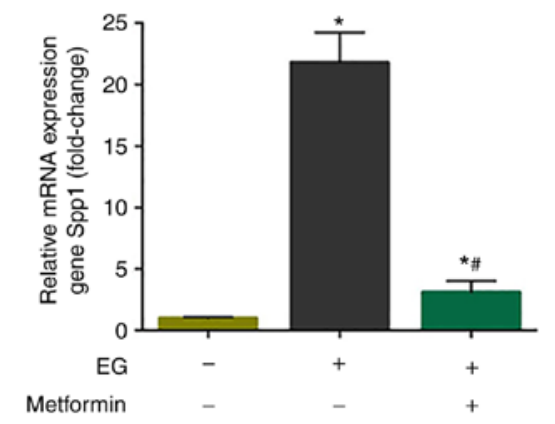

B $\quad(\mathrm{kDa})$
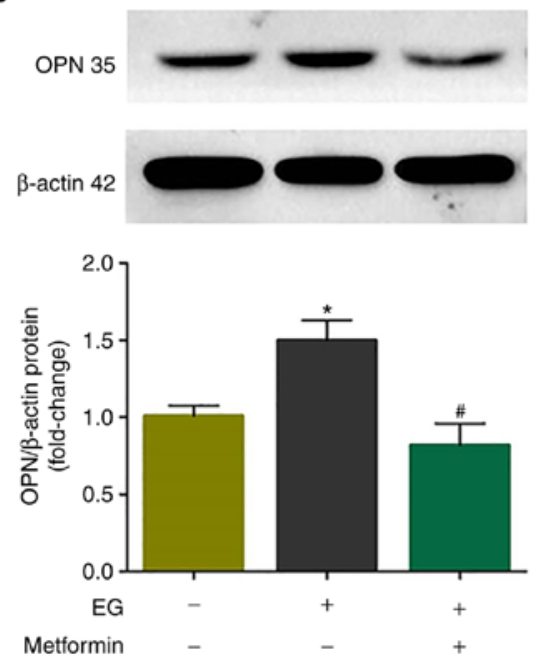

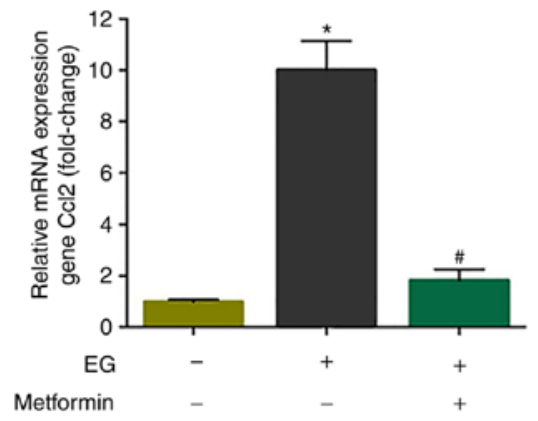

$(\mathrm{kDa})$
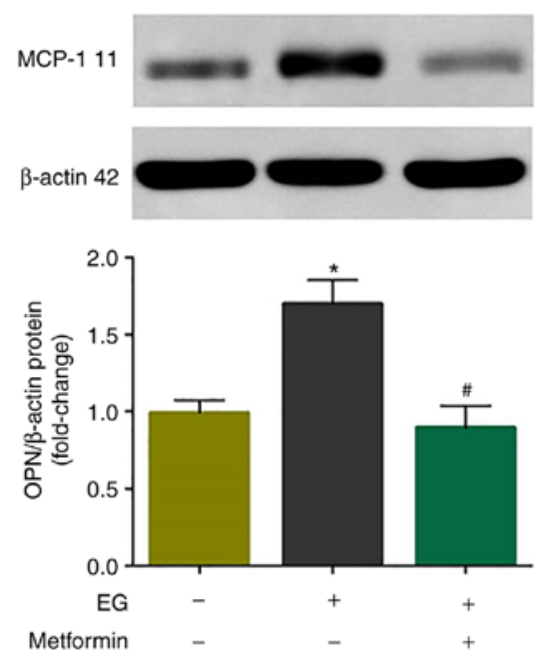

Figure 5. Evaluation of the mRNA transcription and protein expression of OPN and MCP-1 in rat kidneys. (A) Reverse transcription-quantitative polymerase chain reaction analysis of expression levels of OPN (left panel) and MCP-1 (right panel) in rat kidneys; values were corrected for GAPDH. Protein expression of (B) OPN (left panel) and MCP-1 (right panel) in rat kidneys. The data are presented as the mean \pm standard deviation of six independent experiments. $\mathrm{P}<0.05$ vs. control group; ${ }^{\#} \mathrm{P}<0.05$ vs. sodium oxalate group. Statistical analyses were performed by one-way analysis of variance. OPN, osteopontin; MCP-1, monocyte chemoattractant protein 1; EG, ethylene glycol.

and medulla. A grading system and quantitative methods, as described above, were used to evaluate crystal deposition in the kidneys. Compared with the EG + metformin group, crystal formation in the EG group was markedly increased according to the quantitative analysis of the ratio (percentage) of the area containing crystals in the low-powered (magnification, $\mathrm{x} 100)$ field $(\mathrm{P}<0.05$; Fig. 8C). In addition, the number and grade of the renal crystal deposits per 10 fields were markedly decreased in the EG + metformin co-treated group compared with the EG group $(\mathrm{P}<0.05$; Fig. 8D).

\section{Discussion}

Epidemiological and clinical data suggest that there is an increased frequency of kidney stone disease worldwide $(1,3)$. However, with the exception of endoscopic surgery and shock-wave lithotripsy, medical treatment directed at the pathogenesis of nephrolithiasis remains scarce, particularly for $\mathrm{CaOx}$ renal stones (33). The present study demonstrated that metformin ameliorated $\mathrm{CaOx}$ kidney crystal sedimentation in an EG-induced rat model. In addition, metformin treatment markedly decreased the expression of inflammatory genes, including MCP-1 and OPN, which have been demonstrated to be key in the pathogenesis of $\mathrm{CaOx}$ nephrolithiasis $(14-16,26)$. Furthermore, in vitro studies with MDCK and HK-2 cells demonstrated that $\mathrm{Ox}$ increased the expression levels of
MCP-1 and OPN, and that metformin reversed these effects. These findings suggest that metformin markedly prevents the development of $\mathrm{CaOx}$ nephrolithiasis, possibly by inhibiting the expression of MCP-1 and OPN.

Metformin, the first-line treatment for patients with type II diabetes mellitus and the most widely prescribed antidiabetic drug in the world, has several properties, including antioxidant effects, life-extending capabilities and antitumor activity (18). Our previous investigation showed that metformin effectively reduces renal tubular injury resulting from the lipid peroxidation induced by $\mathrm{Ox}$ and inhibit renal crystal deposition in rats (19). Notably, previous investigations have shown that metformin suppresses inflammatory responses and monocyte-to-macrophage differentiation through activation of the AMP-activated protein kinase signaling pathway (34). Restricting the expression of OPN and MCP-1 may be an attractive approach to the treatment of renal crystal deposition (13-15). However, to the best of the authors' knowledge, at present, no studies have demonstrated the effect of metformin on kidney crystal sedimentation by regulating inflammatory mediators OPN and MCP-1.

MCP-1 is a chemokine with potent and specific chemotactic activity towards recruiting monocytes, macrophages and lymphocytes, and its overexpression has been associated with various renal diseases and inflammatory cell infiltration $(35,36)$. Several reports have concluded that MCP-1 may 


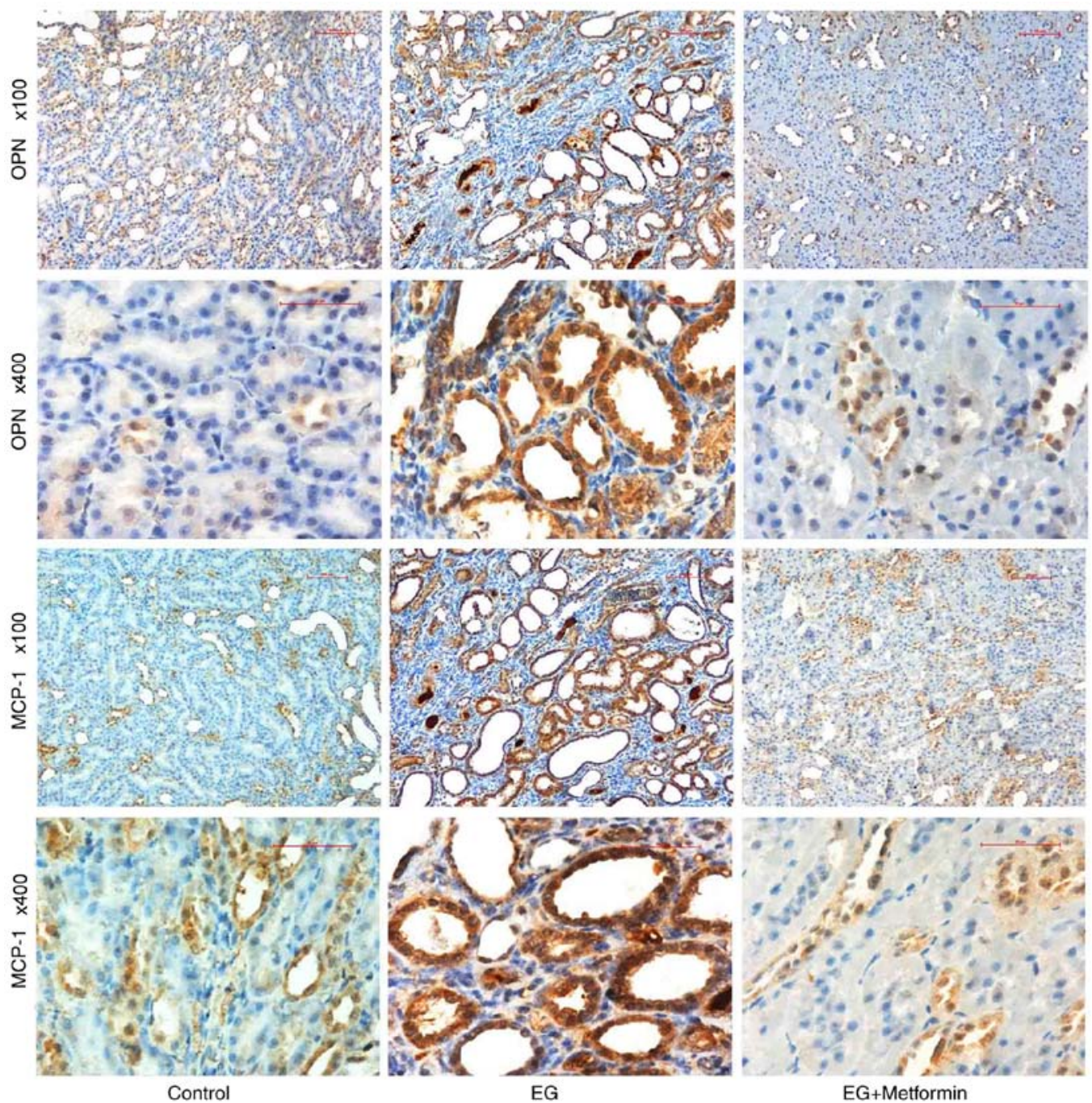

Figure 6. Immunohistochemical distribution of the expression of OPN and MCP-1 in rat kidneys harvested following an 8-week treatment period. The left column comprises representative images showing the expression of OPN and MCP-1 in control rats, the middle column comprises representative images showing the expression of OPN and MCP-1 in EG-treated rats and the right column comprises representative images showing the expression of OPN and MCP-1 in EG + metformin-co-treated rats. OPN, osteopontin; MCP-1, monocyte chemoattractant protein 1; EG, ethylene glycol.


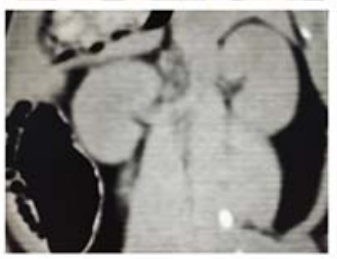

Control $0 / 6$

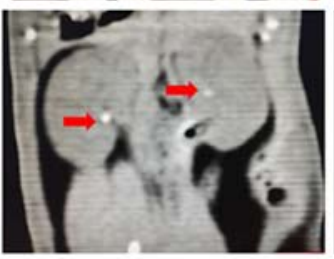

EG 5/6

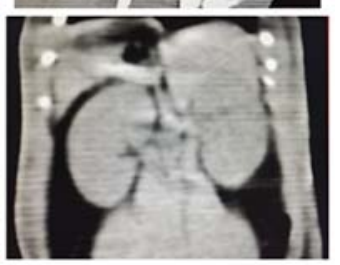

$\mathrm{EG}+$ Metformin 0/6

Figure 7. Crystallization in rat kidneys harvested following 8 weeks of treatment is observed as white dots in the renal parenchyma on thin-slice reconstructions of non-enhanced CT images ( $\mathrm{n}=6$ for each group). The red arrows indicate crystallization formed in the rat kidney tissue. The left column comprises representative images showing the control rats, the middle column comprises representative images showing the EG-treated rats and the right column comprises representative images showing the EG + metformin-co-treated rats. EG, ethylene glycol. 
A
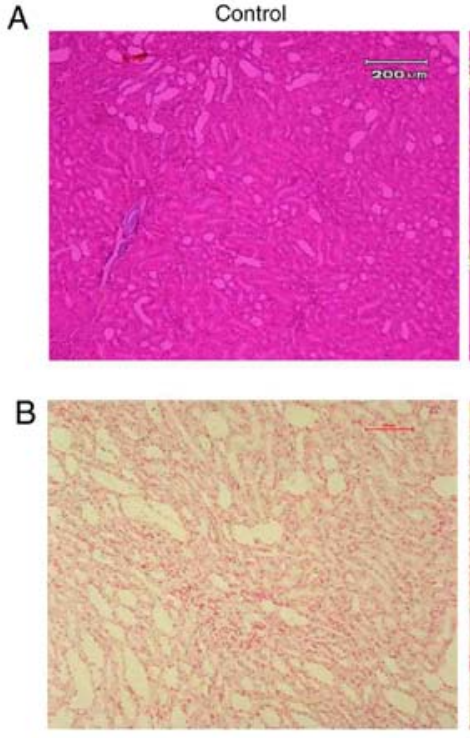

C

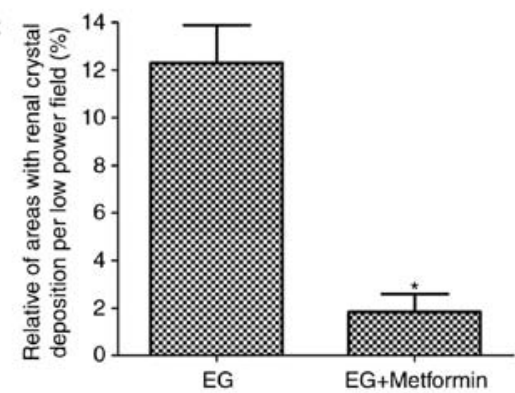

EG
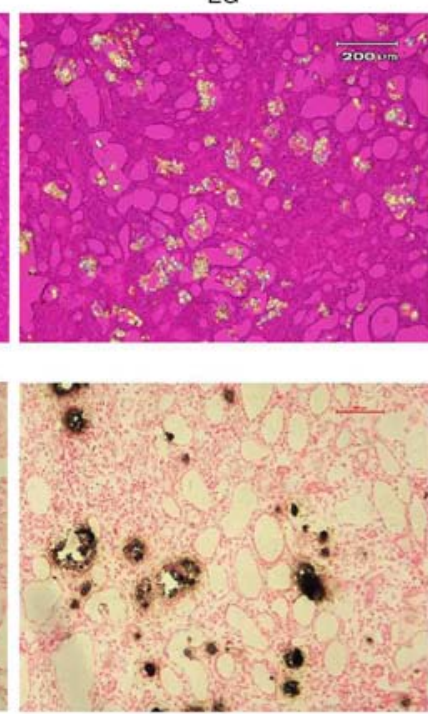

EG+Mettormin
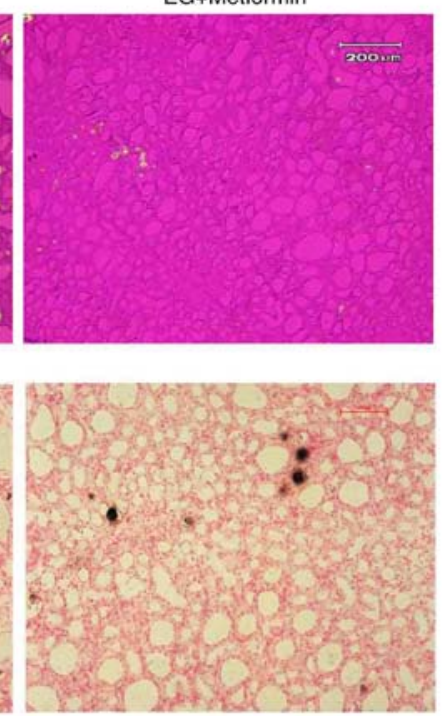

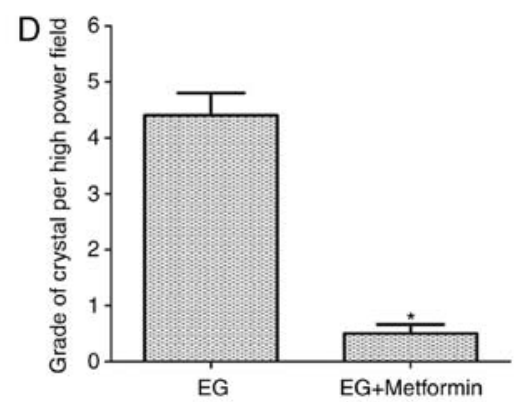

Figure 8. Morphologic distribution and quantitative estimation of renal CaOx crystals. (A) Representative micrographs of renal sections and crystal deposits in the control group, EG group, and EG + metformin group, respectively, using hematoxylin-eosin staining and polarized light optical microphotography. Magnification, x100. (B) Representative micrographs of the control group, EG group, and EG + metformin group, respectively, using Pizzolato staining. Magnification, x100. (C) Ratios of areas with renal crystal deposition per low-powered field were estimated. (D) Grades of calcium oxalate deposits per high-powered field were assessed. " $\mathrm{P}<0.05$ vs. EG group. Statistical analyses were performed using a two-tailed unpaired t-test. EG, ethylene glycol.

be important in the pathogenesis of $\mathrm{CaOx}$ renal crystal deposition $(16,22,37)$. OPN is a glycosylated phosphoprotein involved in various types of inflammatory disease by regulating Th1-type immune responses and the migration of various immune cells (17). Substantial evidence implicates that OPN is pivotal in the development and progression of $\mathrm{CaOx}$ nephrolithiasis $(14,26,38)$. The data obtained in the present study show that metformin prevented the overexpression of MCP-1 and OPN in two Ox-induced renal tubular cell lines. These findings corroborate those of earlier studies demonstrating that metformin significantly attenuates renal cell damage and inflammatory activation induced by $\mathrm{Ox}(16,22)$. Ox exposure has been shown to promote the adherence of crystals to renal epithelial cells and regulate the genes required for molecular functions, biologic pathways and cellular components involved in the pathogenesis of $\mathrm{CaOx}$ nephrolithiasis $(39,40)$, and MCP-1 and OPN have been recognized as major targets in Ox-induced renal diseases $(13,17,35,36)$. In addition, consistent with the in vitro results, the expression levels of MCP-1 and OPN in the kidneys were increased in EG-induced rat models and suppressed by the administration of metformin. Based on these in vivo and in vitro data, the present study clearly indicates that metformin treatment markedly decreases the expression of OPN and MCP-1 in renal tubular cells, although further investigations are required.
The serum biochemistry results showed no significant differences between the experimental groups, with the exception of a small but significant increase of serum $\mathrm{P}$ in the EG group compared with the control group. These findings corroborate those of earlier serum biochemical analyses in an EG-induced rat model (31). In the present study, urinary Ox excretion was significantly higher in the EG and $\mathrm{EG}+$ metformin groups than in the control group, with no differences in urine volume, urinary $\mathrm{pH}$ or $\mathrm{Ca}$ excretion. These results are in accordance with those of previous studies $(31,41)$. Notably, metformin significantly decreased the concentration of urinary Ox compared with that in the EG group. These findings in the urinary biochemistry may be associated with the decreased crystal formation in the kidney of rats co-treated with EG and metformin. Of note, the finding that the crystal formation induced by EG in experimental animals was ameliorated by metformin administration provides potential evidence that inflammation is causally involved in $\mathrm{CaOx}$ stone formation. This is consistent with evidence obtained from other previous studies that anti-inflammatory agents can ameliorate urolithiasis $(10,30,31)$.

The present study inevitably had certain potential limitations. Firstly, the data shown in Fig. 7 were not quantitatively compared. As the thin-slice reconstruction of non-enhanced CT images was a macroscopic inspection, it did not clearly 
show the deposition of very small crystals in kidney tissues. The results indicated that no significant kidney crystals were detected in any field of kidney tissues from the control $(0 / 6)$ group or EG + metformin (0/6) group (crystal depositions can be detected by polarized light optical microscopic examination) in the non-enhanced CT images. Only the rats treated with EG showed renal crystal depositions (5/6) by non-enhanced CT images. Secondly, the concentrations of metformin used in vitro were mainly determined by drug pharmacokinetics and toxicological data. However, a dose of $200 \mathrm{mg} / \mathrm{kg} /$ day metformin was administered in vivo experiment as recommended by in previous study $(27,28)$. The association between metformin levels in vitro and in vivo is not known. As the in vivo environment is a complex ecological environment composed of various types of cells, the drug is likely to be affected by osmotic pressure, various hormones and other factors. However, in vitro cell experiments are experimental models under specific ideal conditions. To date, few studies have specifically linked drug concentrations in in vitro and in vivo experiments $(42,43)$. Thirdly, the experiments did not investigate the effect of metformin on nephrolithiasis in the absence of OPN or MCP-1 by treating animals with anti-OPN and anti-MCP-1 antibodies or by performing the experiments in animals deficient in OPN or MCP-1 for in-depth validation experiments in vivo. Therefore, further investigations are required to identify the exact roles of OPN and MCP-1 in the inhibition of renal stone formation by metformin.

In conclusion, the present study demonstrated that treatment with metformin protected the kidney from EG-induced $\mathrm{CaOx}$ crystal deposition in experimental animals, and that this protection was based on correction of the Ox-induced increased expression of OPN and MCP-1 in renal tubular epithelium cells. Additionally, to the best of our knowledge, the present study is the first to demonstrated in vitro and in vitro that metformin may simultaneously regulate these two molecular targets during the formation of stones. The present study has once again expanded the clinical application potential of metformin and elucidated its possible mechanism of action. These findings establish metformin as a novel prospective therapeutic agent for the treatment of $\mathrm{CaOx}$ stone formation and may benefit individuals with primary hyperoxaluria or recurrent $\mathrm{CaOx}$ stone formation, for whom there are few options for preventative measures, other than increased water intake. These results are particularly noteworthy as metformin, a widely used drug, may be developed for another novel medical application in the future.

\section{Acknowledgements}

Not applicable.

\section{Funding}

This study was supported by grants from the National Natural Science Foundation of China (grant nos. 81700616 and 81472416), the Tianjin Science and Technology Popularization Project (grant no. 15KPXM01SF034), the Science and Technology Fund of Tianjin Municipal Bureau of health (grant no. 2014KZ110), the Science and Technology Program of Tianjin (grant no. 18PTLCSY00020), and the Science and
Technology Fund of Tianjin Health and Family Planning Commission (grant no. 2015KZ102).

\section{Availability of data and materials}

The datasets used and/or analyzed during the current study are available from the corresponding author on reasonable request.

\section{Authors' contributions}

CL designed the experiments, analyzed data and wrote the manuscript. XY performed the experiments, analyzed data and wrote the manuscript. TY performed the experiments and wrote the manuscript. JieL performed the experiments and wrote the manuscript. RY analyzed data and wrote the manuscript. SQ, YZ, LL, JinL, XZ and KY performed the experiments and analyzed data. YX analyzed the data and wrote the manuscript. All authors critically reviewed content and approved the final version for publication.

\section{Ethics approval and consent to participate}

All applicable international, national, and institutional guidelines for the care and use of animals were followed. All animal procedures were conducted in strict compliance with the Guide for the Care and Use of Laboratory Animals published by the US National Institutes of Health (publication no. 85-23; revised 1996; Bethesda, MD, USA). Ethical protocols were approved by the Animal Care and Use Committee of Tianjin Medical University and the Ethics Committees of Tianjin Medical University.

\section{Patient consent for publication}

Not applicable.

\section{Competing interests}

The authors declare that they have no competing interests.

\section{References}

1. Hesse A, Brändle E, Wilbert D, Köhrmann KU and Alken P: Study on the prevalence and incidence of urolithiasis in Germany comparing the years 1979 vs. 2000. Eur Urol 44: 709-713, 2003.

2. Saigal CS, Joyce G and Timilsina AR; Urologic Diseases in America Project: Direct and indirect costs of nephrolithiasis in an employed population: Opportunity for disease management? Kidney Int 68: 1808-1814, 2005.

3. Turney BW, Reynard JM, Noble JG and Keoghane SR: Trends in urological stone disease. BJU Int 109: 1082-1087, 2012.

4. Knoll T, Schubert AB, Fahlenkamp D, Leusmann DB Wendt-Nordahl G and Schubert G: Urolithiasis through the ages: Data on more than 200,000 urinary stone analyses. J Urol 185: 1304-1311, 2011.

5. Yang X, Zhang C, Qi S, Zhang Z, Shi Q, Liu C, Yang K, Du E $\mathrm{Li}$ N, Shi J and Xu Y: Multivariate analyses of urinary calculi composition: A 13-year single-center study. J Clin Lab Anal 30: 873-879, 2016.

6. Milliner DS, Wilson DM and Smith LH: Phenotypic expression of primary hyperoxaluria: Comparative features of types I and II. Kidney Int 59: 31-36, 2001.

7. Pearle MS, Calhoun EA and Curhan GC; Urologic Diseases of America Project: Urologic diseases in America project: Urolithiasis. J Urol 173: 848-857, 2005. 
8. Kumar S, Sigmon D, Miller T, Carpenter B, Khan S, Malhotra R, Scheid $\mathrm{C}$ and Menon M: A new model of nephrolithiasis involving tubular dysfunction/injury. J Urol 146: 1384-1389, 1991.

9. Kim HH, Kwak C, Jeong BC and Kim SW: Effect of oxalate on the growth of renal tubular epithelial cells. J Endourol 16 261-264, 2002.

10. Fujii Y, Okada A, Yasui T, Niimi K, Hamamoto S, Hirose M, Kubota Y, Tozawa K, Hayashi Y and Kohri K: Effect of adiponectin on kidney crystal formation in metabolic syndrome mode mice via inhibition of inflammation and apoptosis. PLoS One 8 e61343, 2013.

11. Khan SR: Reactive oxygen species as the molecular modulators of calcium oxalate kidney stone formation: Evidence from clinical and experimental investigations. J Urol 189: 803-811, 2013.

12. Taguchi K, Okada A, Hamamoto S, Iwatsuki S, Naiki T, Ando R, Mizuno K, Tozawa K, Kohri K and Yasui T: Proinflammatory and metabolic changes facilitate renal crystal deposition in an obese mouse model of metabolic syndrome. J Urol 194: $1787-1796,2015$

13. Rovin BH and Phan LT: Chemotactic factors and renal inflammation. Am J Kidney Dis 31: 1065-1084, 1998.

14. Wesson JA, Johnson RJ, Mazzali M, Beshensky AM, Stietz S, Giachelli C, Liaw L, Alpers CE, Couser WG, Kleinman JG and Hughes J: Osteopontin is a critical inhibitor of calcium oxalate crystal formation and retention in renal tubules. J Am Soc Nephrol 14: 139-147, 2003.

15. Khan SR and Kok DJ: Modulators of urinary stone formation. Front Biosci 9: 1450-1482, 2004.

16. Umekawa T, Chegini $\mathrm{N}$ and Khan SR: Oxalate ions and calcium oxalate crystals stimulate MCP-1 expression by renal epithelial cells. Kidney Int 61: 105-112, 2002.

17. Morimoto J, Kon S, Matsui Y and Uede T: Osteopontin; as a target molecule for the treatment of inflammatory diseases. Curr Drug Targets 11: 494-505, 2010.

18. Novelle MG, Ali A, Diéguez C, Bernier M and de Cabo R: Metformin: A hopeful promise in aging research. Cold Spring Harb Perspect Med 6: a025932, 2016.

19. Yang X, Ding H, Qin Z, Zhang C, Qi S, Zhang H, Yang T, He Z, Yang K, Du E, et al: Metformin prevents renal stone formation through an antioxidant mechanism in vitro and in vivo. Oxid Med Cell Longev 2016: 4156075, 2016.

20. Cavaglieri RC, Day RT, Feliers D and Abboud HE: Metformin prevents renal interstitial fibrosis in mice with unilateral ureteral obstruction. Mol Cell Endocrinol 412: 116-122, 2015.

21. Park HK, Jeong BC, Sung MK, Park MY, Choi EY,Kim BS, Kim HH and Kim JI: Reduction of oxidative stress in cultured renal tubular cells and preventive effects on renal stone formation by the bioflavonoid quercetin. J Urol 179: 1620-1626, 2008.

22. Umekawa T, Iguchi M, Uemura $\mathrm{H}$ and Khan SR: Oxalate ions and calcium oxalate crystal-induced up-regulation of osteopontin and monocyte chemoattractant protein-1 in renal fibroblasts. BJU Int 98: 656-660, 2006.

23. Huang MY, Chaturvedi LS, Koul S and Koul HK: Oxalate stimulates IL-6 production in HK-2 cells, a line of human renal proximal tubular epithelial cells. Kidney Int 68: 497-503, 2005.

24. Li Y and McMartin KE: Strain differences in urinary factors that promote calcium oxalate crystal formation in the kidneys of ethylene glycol-treated rats. Am J Physiol Renal Physiol 296 : F1080-F1087, 2009

25. Green ML, Hatch M and Freel RW: Ethylene glycol induces hyperoxaluria without metabolic acidosis in rats. Am J Physiol Renal Physiol 289: F536-F543, 2005.

26. Khan SR, Johnson JM, Peck AB, Cornelius JG and Glenton PA Expression of osteopontin in rat kidneys: Induction during ethylene glycol induced calcium oxalate nephrolithiasis. J Urol 168: 1173-1181, 2002.

27. Quaile MP, Melich DH, Jordan HL, Nold JB, Chism JP, Polli JW, Smith GA and Rhodes MC: Toxicity and toxicokinetics of metformin in rats. Toxicol Appl Pharmacol 243: 340-347, 2010.

28. Matveyenko AV, Dry S, Cox HI, Moshtaghian A, Gurlo T, Galasso R, Butler AE and Butler PC: Beneficial endocrine but adverse exocrine effects of sitagliptin in the human islet amyloid polypeptide transgenic rat model of type 2 diabetes: Interactions with metformin. Diabetes 58: 1604-1615, 2009.
29. Livak KJ and Schmittgen TD: Analysis of relative gene expression data using real-time quantitative PCR and the 2(-Delta Delta C(T)) method. Methods 25: 402-408, 2001.

30. Taguchi K, Okada A, Kitamura H, Yasui T, Naiki T, Hamamoto S, Ando R, Mizuno K, Kawai N, Tozawa K, et al: Colony-stimulating factor-1 signaling suppresses renal crystal formation. J Am Soc Nephrol 25: 1680-1697, 2014.

31. Taguchi K, Okada A, Yasui T, Kobayashi T, Ando R, Tozawa K and Kohri K: Pioglitazone, a peroxisome proliferator activated receptor $\gamma$ agonist, decreases renal crystal deposition, oxidative stress and inflammation in hyperoxaluric rats. J Urol 188: 1002-1011, 2012.

32. Tsujihata M, Momohara C, Yoshioka I, Tsujimura A, Nonomura N and Okuyama A: Atorvastatin inhibits renal crystal retention in a rat stone forming model. J Urol 180: 2212-2217, 2008

33. Moe OW: Kidney stones: Pathophysiology and medical management. Lancet 367: 333-344, 2006.

34. Vasamsetti SB, Karnewar S, Kanugula AK, Thatipalli AR, Kumar JM and Kotamraju S: Metformin inhibits monocyte-to-macrophage differentiation via AMPK-mediated inhibition of STAT3 activation: Potential role in atherosclerosis. Diabetes 64: 2028-2041, 2015.

35. Matsushita Y, Ogawa D, Wada J, Yamamoto N, Shikata K, Sato C, Tachibana $\mathrm{H}$, Toyota $\mathrm{N}$ and Makino $\mathrm{H}$ : Activation of peroxisome proliferator-activated receptor delta inhibits streptozotocin-induced diabetic nephropathy through anti-inflammatory mechanisms in mice. Diabetes 60: 960-968, 2011.

36. Grandaliano G, Gesualdo L, Ranieri E, Monno R, Montinaro V, Marra F and Schena FP: Monocyte chemotactic peptide-1 expression in acute and chronic human nephritides: A pathogenetic role in interstitial monocytes recruitment. J Am Soc Nephrol 7: 906-913, 1996.

37. Umekawa T, Tsuji H, Uemura $H$ and Khan SR: Superoxide from NADPH oxidase as second messenger for the expression of osteopontin and monocyte chemoattractant protein-1 in renal epithelial cells exposed to calcium oxalate crystals. BJU Int 104: 115-120, 2009.

38. Okada A, Nomura S, Saeki Y, Higashibata Y, Hamamoto S, Hirose M, Itoh Y, Yasui T, Tozawa K and Kohri K: Morphological conversion of calcium oxalate crystals into stones is regulated by osteopontin in mouse kidney. J Bone Miner Res 23: 1629-1637, 2008.

39. Koul S, Khandrika L, Meacham RB and Koul HK: Genome wide analysis of differentially expressed genes in HK-2 cells, a line of human kidney epithelial cells in response to oxalate. PLoS One 7: e43886, 2012.

40. Koul HK, Koul S, Fu S, Santosham V, Seikhon A and Menon M: Oxalate: From crystal formation to crystal retention. J Am Soc Nephrol 10 (Suppl 14): S417-S421, 1999

41. Itoh Y, Yasui T, Okada A, Tozawa K, Hayashi Y and Kohri K: Preventive effects of green tea on renal stone formation and the role of oxidative stress in nephrolithiasis. J Urol 173: 271-275, 2005.

42. Pearlstein RA, McKay DJJ, Hornak V, Dickson C, Golosov A, Harrison T, Velez-Vega C and Duca J: Building new bridges between in vitro and in vivo in early drug discovery: Where molecular modeling meets systems biology. Curr Top Med Chem 17: 2642-2662, 2017

43. Jaroch K, Jaroch A and Bojko B: Cell cultures in drug discovery and development: The need of reliable in vitro-in vivo extrapolation for pharmacodynamics and pharmacokinetics assessment. J Pharm Biomed Anal 147: 297-312, 2018.

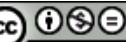

This work is licensed under a Creative Commons Attribution-NonCommercial-NoDerivatives 4.0 International (CC BY-NC-ND 4.0) License. 